\title{
Estimating the Impact of the
} COVID-19 Pandemic on Maternal and Perinatal Health Care Services in Italy: Results of a Self-Administered Survey

\author{
Loredana Cena ${ }^{1 *}$, Matteo Rota ${ }^{2}$, Stefano Calza ${ }^{2}$, Barbara Massardi ${ }^{3}$, Alice Trainini ${ }^{1}$ and \\ Alberto Stefana ${ }^{1}$
}

${ }^{1}$ Observatory of Perinatal Clinical Psychology, Section of Neuroscience, Department of Clinical and Experimental Sciences, University of Brescia, Brescia, Italy, ${ }^{2}$ Units of Biostatistics and Biomathematics and Bioinformatics, Department of Molecular and Translational Medicine, University of Brescia, Brescia, Italy, ${ }^{3}$ Department of Clinical Sciences and Community Health,

University of Milan, Milan, Italy

OPEN ACCESS

Edited by:

Rahul Shidhaye,

Pravara Institute of Medical

Sciences, India

Reviewed by:

Francesco Chirico,

Catholic University of the Sacred

Heart, Italy

Vincent Sethare,

University of Botswana, Botswana

*Correspondence:

Loredana Cena

loredana.cena@unibs.it

orcid.org/0000-0002-3162-9237

Specialty section:

This article was submitted to

Public Mental Health

a section of the journal

Frontiers in Public Health

Received: 28 April 2021

Accepted: 18 June 2021

Published: 16 July 2021

Citation:

Cena L, Rota M, Calza S, Massardi B,

Trainini A and Stefana A (2021)

Estimating the Impact of the COVID-19 Pandemic on Maternal and Perinatal Health Care Services in Italy: Results of a Self-Administered Survey.

Front. Public Health 9:701638.

doi: 10.3389/fpubh.2021.701638
The coronavirus disease 2019 (COVID-19) pandemic is strongly changing the way most people live their lives, and disrupting specialist healthcare systems. Such public health disruptions have resulted in significant collateral damage with particular implications for vulnerable populations, including the perinatal population. This Study aims to estimate the impact of the COVID-19 pandemic on Italian maternal and perinatal health care services. A questionnaire was designed to evaluate the COVID-19 impact on Italian maternal and perinatal healthcare facilities and their activities and provision of services from March to May 2020. The survey was completed by hospital-based and community-based Italian maternal and perinatal healthcare facilities. Most of these were located in Lombardy or Veneto (the most affected Italian regions). $70 \%$ of all facilities reported that the first wave of the COVID-19 pandemic negatively influenced the functioning of one or more aspects of the perinatal service; only $28.4 \%$ of facilities all over the country continued to provide outpatient routine visits and examinations as usual; $23.4 \%$ of facilities became understaffed during the index period due to various reasons such as ward transfer and sick leave. This is the first Italian study, and among very few international studies that describe the effects of the COVID-19 pandemic on antenatal and postnatal healthcare facilities and their provision of activities and services. Our findings confirm that healthcare systems even in high-income countries were not entirely prepared to handle such a global health emergency; indeed, specialized maternal and perinatal healthcare services have been disrupted by this global health emergency.

Keywords: health services, antenatal and postnatal healthcare services, newborn's health, women's health, public health, maternal services

\section{INTRODUCTION}

The coronavirus disease 2019 (COVID-19) pandemic quickly and widely spread from the Hubei Province in the People's Republic of China, where the virus originated in December 2019 , throughout the world, starting in early $2020(1,2)$. It has extensively changed the way most people live their daily life, including interpersonal relationships and health habits (3). 
Furthermore, the morbidity and mortality associated with severe acute respiratory syndrome coronavirus 2 (SARS-CoV2) infection have put healthcare systems worldwide under great strain (4) and also disrupted a variety of general and specialist health facilities that deliver non-COVID-19 health care services (5-10). These disruptions to public health have resulted in significant collateral damage with particular implications for vulnerable populations (11-13), including the perinatal population $(7,14-16)$.

Italy was the second epicenter of the spread of COVID-19 (17) and major changes have been made to the provision of health services since the outbreak in March 2020 (see Table 1). The initial rapid spread of infections and the limited number of intensive care beds available posed a critical threat to the Italian national health system (18) and its workers (thousands of healthcare professionals have been infected by the virus and many of them have died) $(19,20)$. Healthcare facilities constituted the main source of virus outbreaks because of hospital overcrowding and the existence of asymptomatic cases of the virus (21). After this first wave of pandemic, which ended in May 2020, the Italian government implemented significant changes to the structure of the health system in order to stem the second wave (22). However, the effects were different in different regions. The severity and the mortality of COVID-19 infection in Lombardy (which was the Italian epicenter) and Veneto were higher during this first wave of pandemic than during the second wave (between October 2020 and January 2021). For instance, in Lombardy there were 16,362 deaths $(47.7 \%$ of deaths in Italy) during the first wave and 15,515 deaths (18.9\% of deaths in Italy) during the second and the third wave combined $(23,24)$. But this does not apply to the rest of Italy, where the trend in mortality was reversed: 34,260 and 38,535 deaths in the first and second wave, respectively $(23,24)$.

To date, COVID-19 studies in Italy have reported the disruption of services and substantial changes in the way clinical care is delivered for mental health (25), oncology (26), surgical arthroplasty (27), pediatrics (28) and many other specialist healthcare systems. However, at the time of writing, the status of the perinatal healthcare system has not yet been comprehensively or extensively investigated. Therefore, we sought to evaluate the impact of the COVID-19 outbreak and the containment measures on maternal and perinatal healthcare services in Italy.

TABLE 1 | Timeline of the COVID-19 pandemic in Italy.

December 31, 2019

January 9, 2020

January 17, 2020

January 22, 2020

January 30, 2020

January 31, 2020

February 21, 2020

March 8-9, 2020

March 11, 2020

March 13, 2020

March 31, 2020

April, 2020

May 4, 2020

May 31,2020
The Wuhan Municipal Health Commission in Wuhan City, Hubei province, China, reports a cluster of pneumonia cases (including seven severe cases) of unknown etiology.

China CDC reports that a novel coronavirus (later named SARS-CoV-2, the virus causing COVID-19) had been detected as the causative agent for 15 of the 59 cases of pneumonia.

ECDC publishes its first risk assessment on the novel coronavirus

The Italian Ministry of Health instructs a task force to coordinate a surveillance system for suspected cases and interventions in national territory.

Two Chinese tourists hospitalized for respiratory tract infection are the first confirmed cases of COVID-19 detected in Italy. The WHO declares this first outbreak of novel coronavirus a "public health emergency of international concern."

The Italian Council of Ministers declares a national public health emergency condition.

The Italian National Institute of Health confirms the first case of local transmission of COVID-19 infection. Over the following days, the Italian authorities reported clusters of cases in several regions (Lombardy, Piedmont, Veneto etc.).

The Italian Council of Ministers issues a decree to install strict public health measures starting in the most affected regions (i.e., Lombardy and Veneto). These measures include social distancing and restricting movements of people within and outside the hometown, with permitted travel limited to shopping for food, going to work (only for essential services to remain operating; work from home is encouraged), or seeking medical care. All planned surgeries are postponed in order to give over intensive care beds to the treatment of COVID-19 patients.

The Director General of the WHO declares COVID-19a "global pandemic." The Italian Council of Ministers extends the strict containment measures at national level.

The $\mathrm{WHO}$ declares Europe is becoming the new epicenter of COVID-19 pandemic.

Official reports indicated 7,593 COVID-19-associated deaths and 44,773 infected individuals. The Italian Ministry of Health issues recommendations for pregnant women, women in labor, puerperal women, newborns and breastfeeding mothers.

Italian scientific associations in the field of perinatal medicine (e.g., FIGO and SIN) start to publish interim recommendations for management of pregnant-woman in labor, puerperal women, newborns and breastfeeding mothers during the COVID-19 pandemic. The Italian Council of Ministers restores the freedom of movement, and other non-essential activities re-open later in the month. The Istituto Superiore di Sanità (in collaboration with ACP, AGUI, AOGOI, FNOPO, SIAARTI, SIGO, SIMP, SIN, SIP, and TAS) publishes interim indications for pregnancy, childbirth, breastfeeding and the care of very young children 0-2 years in response to the COVID-19 emergency.

Table adapted from the Timeline of ECDC's response to COVID-19 (available on-line at www.ecdc.europa.eu/en/covid-19/timeline-ecdc-response).

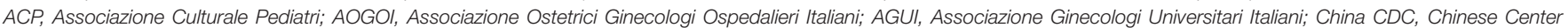

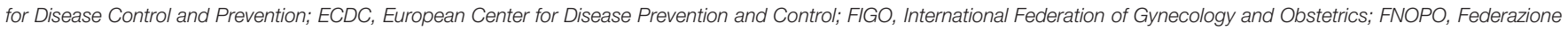

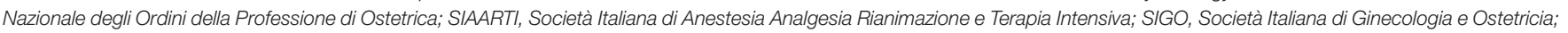

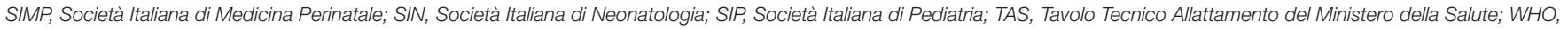
World Health Organization. 


\section{METHODS}

\section{Study Design and Participants}

A cross-sectional survey was conducted using an online questionnaire accessible on the University of Brescia website. The questionnaire was distributed via an electronic link to the coordinators or representatives of 1,428 public and private maternal and perinatal healthcare centers located throughout Italy. A brief explanation of the study purpose and assurance of anonymity was outlined in the body of the email as well as on the first page of the questionnaire. Informed written consent was obtained from all respondents before data collection. The research was approved by the Ethics Committee of ASST Spedali Civili Hospital Brescia, Italy (Approval number: NP4221 24.06.2020). The questionnaire was made available for completion from June 30 to October 7, 2020. Data were collected using LimeSurvey.

\section{Survey Description}

The survey questionnaire was specifically created for this study: to evaluate the COVID-19 impact on both antenatal and postnatal healthcare facilities and their activities and provision of services. It was designed and trialed by a team of perinatal experts who work in maternal and perinatal clinics or are regularly involved in research in this area and in the training of healthcare workers. All the experts are members of the Observatory of Perinatal Clinical Psychology (https://www.unibs. it/it/node/988), Section of Neuroscience of the Department of Clinical and Experimental Sciences (University of Brescia, Italy). Possible misinterpretations or difficulties with wording or comprehension were discussed and resolved within the core research group. The final version of the survey questionnaire included 60 general questions, 4 additional specific questions for antenatal services and 13 for intrapartum, postnatal services. Most of the questions were closed-ended, but some optional open-ended questions were used to allow respondents to express their subjective perceptions. An example of the survey questions is "How many healthcare professionals are employed in your facility?" or "Was your facility converted into COVID-19 units during the period of health emergency (March-May 2020)?" For the latter question there were three closed-ended responses: "Yes, completely," "Yes, but only partially," "No".

\section{Statistical Analysis}

Descriptive analyses were performed. Categorical variables were recorded in terms of frequency and compared across groups using the chi-square test or the Fisher's exact test, as appropriate. Analyses were performed using R version 4.0.2 (R Foundation for statistical computing, Vienna, Austria).

\section{RESULTS}

\section{Sample Characteristics}

Seventy-seven Italian perinatal healthcare facilities completed the survey (response rate 5.4\%). Of these, 46 were prenatal facilities, whereas 31 were intrapartum/postnatal or maternal facilities. Thirty-nine were located in Lombardy or Veneto (the most affected Italian regions), and the remaining were from the other ten regions. Twenty-five were hospital-based, whereas the remaining were community-based. The median of healthcare professionals working in the facilities was 10 (inter-quartile range $=37.7$ ).

All the results, unless otherwise specified, did not yield significant differences between hospital- and communitybased facilities, geographical areas, or antenatal and intrapartum/postnatal care.

\section{Services}

Seventy percent of all facilities reported that the first wave of the COVID-19 pandemic negatively influenced the functioning of one or more aspects of the maternal and perinatal services. The impact of the measures taken to prevent the spread of the virus on specific activities and services provided by Italian perinatal healthcare facilities is reported in Table 2.

\section{Visits and Examinations}

From March to May 2020, only 28.4\% of facilities all over the country continued to provide outpatient routine visits and examinations as usual, $59.4 \%$ provided visits but to a limited extent, while $12.2 \%$ ceased their activities. However, the majority of maternal and perinatal facilities were available for emergencies, either completely $(68.8 \%)$ or to a limited extent (19.7\%). All the facilities in which emergency visits were ceased were communitybased and, except one, were located in Lombardy or Veneto. Regarding the waiting time for first visits and control visits, most centers reported that it was not extended (61.2 and 55.4\%, respectively) or only partially (29.3 and $33.8 \%$, respectively). Most of the facilities (68.8\%; 78.3\% prenatal vs. $54.8 \%$ postnatal, $p=0.03$ ) had always or almost always kept fathers out of their partners' visits and exams.

Overall, at $24.7 \%$ of the facilities a part of the staff, and at $6.5 \%$ of the facilities, all the staff, continued their job in smart working mode. Most facilities continued to provide always, or almost always, in-person visits with physicians (82\%), obstetricians $(82.6 \%)$, and nurses $(77.1 \%)$ during the pandemic. On the other hand, only $32.8 \%$ of facilities always or almost always provided in-person psychological visits. The facilities located in Lombardy or Veneto significantly more frequent in-person visits with physicians, compared to those located in the other regions, (91.3 and $74.1 \%$, respectively, $p=0.04$ ) and by psychologists (38.9 and $25.0 \%$, respectively, $p=0.02$ ). At the same time, obstetrician and nurse visits were significantly more frequently used by hospitalbased professionals than by community-based colleagues $(90.5$ vs. $79.2 \%, p=0.02$ for obstetricians; 88.2 vs. $66.7 \%, p=0.02$ for nurses).

\section{Transformation Into a Dedicated COVID Facility}

About a quarter of maternal or perinatal healthcare facilities (23.4\%) were partially converted or transformed into COVID19 units (16 out of 18 of these facilities were hospital-based) to provide care and support to the large number of patients infected by the severe acute respiratory syndrome coronavirus 2 (SARSCoV-2). Further, two facilities (2.6\%), that is, a hospital-based 
TABLE 2 | Impact on activities and services provided by perinatal healthcare facilities in the Italian national territory.

Outpatients care

Inpatients care

Outpatients care

Pregnancy and antenatal care

Postnatal \& newborn care

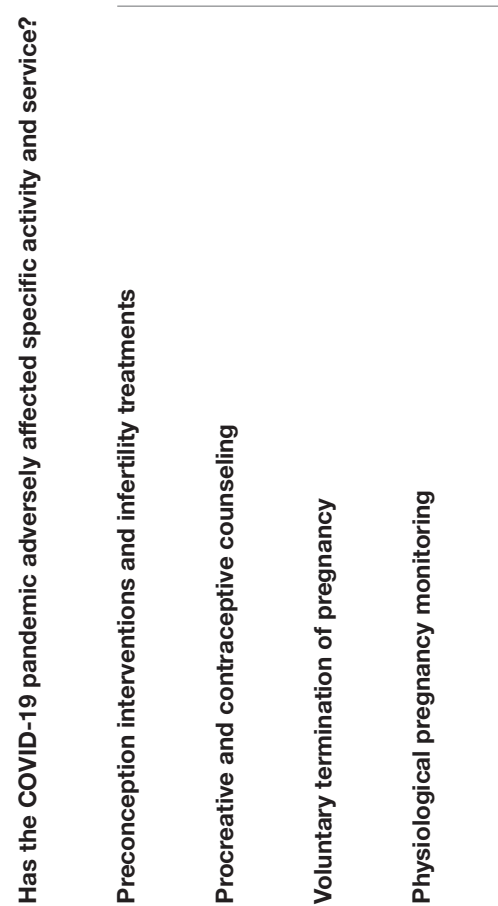

Postnatal \& newborn care

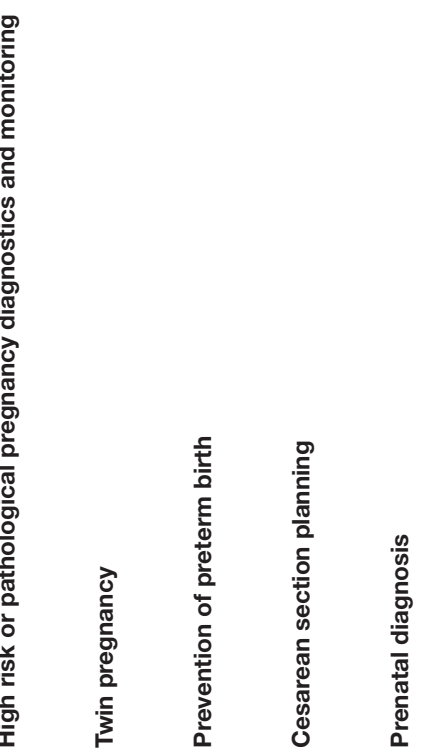

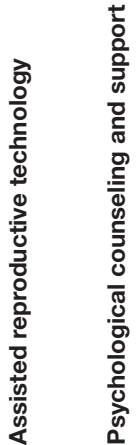


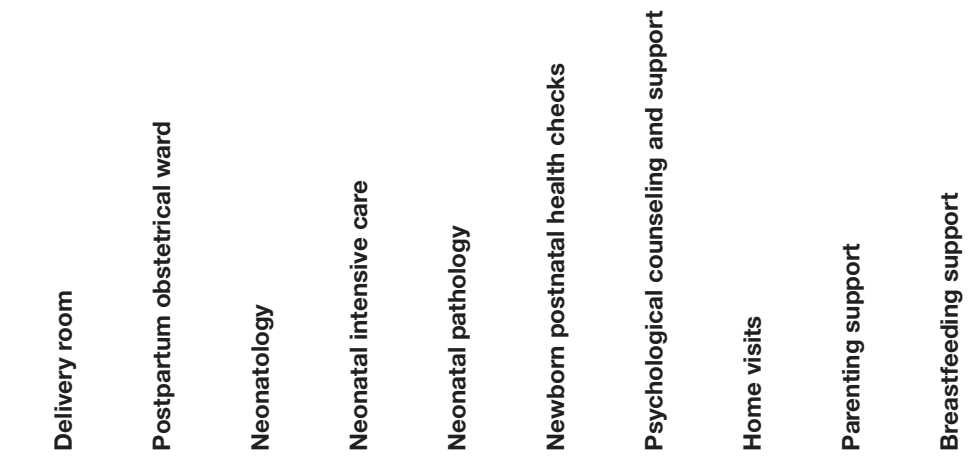

Yes

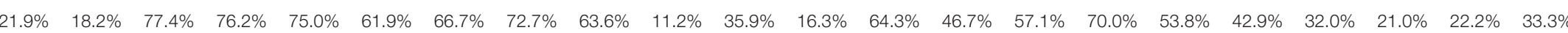

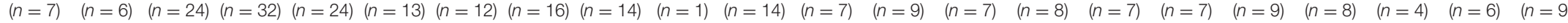

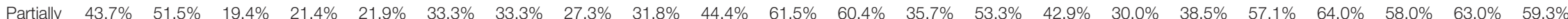

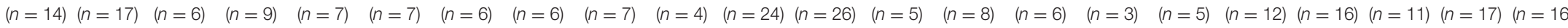

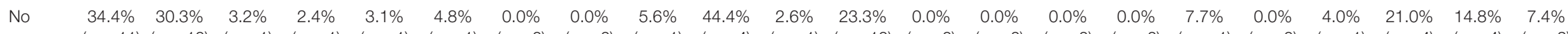

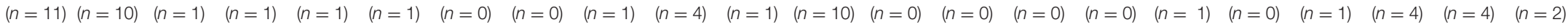

Yes, performed; Partially, partially performed; No, not performed.

Due to the characteristics of the data, it was not possible to calculate differences between hospital- and community-based facilities, nor between geographical areas. 
obstetrics and gynecology ward and a community-based birth center, were completely converted into COVID-19 facilities.

\section{Staff}

Overall, a minority of facilities reported that some or all of the staff members (13 and 3.9\%, respectively) were transferred to COVID-19 wards. This occurred significantly more frequently in hospital-based facilities than in community-based facilities. Nevertheless, almost one-fourth (23.4\%) of the facilities, both hospital- and community-based, became understaffed during the index period due to various reasons such as ward transfer and sick leave.

About half of the facilities (46.0\%) provided the entire staff with specific training on COVID-19 management, whereas a further $28.6 \%$ provided it only to select staff members. The remaining $25.4 \%$ did not provide any training.

Regarding the use of personal protective equipment (PPE) and the adoption of social/physical distancing, though perceived as essential and health-saving, both were considered very stressful by the staff of $68.2 \%$ of the facilities.

\section{DISCUSSION}

Our survey provides sobering insights into disruption to care and treatment for peripartum and perinatal patients (i.e., pregnant women, new mothers and their fetus/neonate) in Italy. We analyzed responses from 77 facilities in 11 Italian regions, covering relevant aspects of the activities and services provided in ante-, intra-, and post-partum clinical settings. Our data aligns with similar studies $(6,29)$ revealing that the pandemic has caused disruptions, with delays, reductions or cancellations in both maternal and neonatal appointments.

Regarding check-ups and examinations, although it is fully understandable that non-urgent services, such as many routine outpatient visits, were canceled in a well-intentioned effort to contain the spread of the new coronavirus (e.g., reports clearly show that, due to the pandemic, fewer women received followup care after obstetric anesthesia) (30). This change in access to medical and health services adversely affected the standard of maternal and perinatal care, including the realm of mental health care but particularly that of preventive, routine, and corrective medicine $(5,6,29)$. The peripartum/perinatal population is particularly vulnerable, both physically and psychologically, to altered or delayed health care, because patients need and deserve close longitudinal monitoring (31). This is true for all pregnant and postpartum women as well as their babies because, for instance, even in case of a healthy young woman with noncomplicated pregnancy (at least for a certain period), a complex maternal condition or fetal anomaly requiring multiple medical subspecialty consultations could occur. We must bear in mind that routine appointments are crucial to enable parents to participate in a shared decision-making process in all the cases in which there is uncertainty about medical conditions (32). Additionally, these consultations may also alleviate unnecessary parental anxiety. All these aspects must be considered when working during disasters such as the ongoing pandemic because, as highlighted by a systematic review on the effects of disaster on pregnancy and the postpartum period, they have an indirect impact on maternal mental health and some perinatal health outcomes (33). Moreover, it has been observed that the welldocumented negative influence of mother's mental health on child development $(34,35)$ may be even greater after a disaster than any direct effect of disaster-related prenatal stress (33).

As regards telehealth (vs in-person check-ups), our data aligns with previous studies showing that it has been rapidly adopted in perinatal care since the onset of the pandemic (36-39). Telehealth offers safe access to consultation and follow-up appointments, saving patients both time and money, but is a complex system that normally requires years of implementation and optimization (40) in order to be an effective tool for providing comprehensive and multidisciplinary perinatal care, mainly in cases where physical examination is not or is rarely necessary. Face-to-face check-ups are still essential in high-risk cases (41). However, in certain cases, such as women with gestational diabetes mellitus, self-care programs via telemedicine may be a better choice than face-to-face visits (42).

In terms of healthcare workers, obstacles to effective care appear to include understaffing and additional stress for perinatal healthcare workers, and this aligns with the previously demonstrated increase in stress during the pandemic, stemming from staff shortages, excessive workload and the use of personal protective equipment (43). In terms of the patient's couple relationship, keeping patients (mothers and babies) together with their partner/other parent is crucial for respectful and effective care. However, consistently with other studies $(5,44,45)$, our data show that partners/other parents are often excluded from the mother's check-ups and examinations in an effort to protect other patients and staff from infection.

As concerns the regional differences, our results indicate that facilities located in Lombardy or Veneto experienced a greater reduction in the provision of outpatient visits, especially emergency visits, and a statistically significant higher percentage of closures of community-based facilities. This is in line, on the one hand, with the Italian geographical distribution of the infection (northern regions faced disproportionately higher numbers of infections and deaths compared with southern and central Italy) (46), and on the other hand, with other Italian studies showing significant variations across regions in the way COVID-19 has affected medical specialist departments [e.g., radiology has changed during the pandemic with a large variability among different Italian regions; (47)]. With regard to the main difference between antenatal and postnatal services, that is, the degree to which fathers are permitted to attend their partners' visits and exams, one plausible and economical explanation is that different regions adopted different approaches to patient care, for instance different Italian regions implemented different strategies in terms of hospitalization, treatment in ICUs or home care for patients infected with SARS-CoV-2 (48). Here, we point out that Italian health system is regionally decentralized (thus, Italy has twenty regional health services), a situation that is not useful in controlling a pandemic, especially if we take into account the strong political pressure toward the transfer of tax resources from the central (national) government to the regions where income is produced (49). 
Taken as a whole, the results of this study suggest that Italy was not entirely prepared to handle such a pandemic; indeed, specialist perinatal healthcare services have been (and still are) disrupted at many levels by this global health emergency. This is in line with other COVID-19 studies that have reported similar situations in other high-income countries $(5,29,36-$ $41,43-45,49-51)$. Our findings deepen the understanding of how the pandemic has influenced Italian healthcare facilities, and can be crucial in guiding the development and implementation of effective responses and, more broadly, in supporting and strengthening perinatal health systems. From this perspective, crises are also times of opportunity (12). The COVID-19 pandemic has caused us to rethink how to improve access to and implementation of perinatal healthcare services. The improvements forced by the current pandemic will be useful during the next phases as well as during future possible national or global health crises.

\section{Strengths and Limitations}

The main strength of this research is that it is the first Italian study, and among very few international studies, that describe the effects of the COVID-19 pandemic on healthcare facilities and their provision of services. Thus, it may be helpful for the formulation of appropriate and evidence-based actions to be taken. However, in interpreting these results, certain limitations must be considered. First, the low response rate (5.4\%) and of the fact that certain Italian regions are poorly represented or absent from the study. Thus, the results may not be representative of all perinatal healthcare facilities in Italy. However, it should be kept in mind that low response rates to online surveys in primary care are common and the extent to which results are affected is uncertain (52). Second, there is no information on the geographic location (urban vs. rural), patient volumes, and demographic characteristics of the responding facilities.

\section{CONCLUSION}

The COVID-19 pandemic has disrupted maternal and perinatal healthcare activities and services, as well as increasing levels of stress among healthcare providers. This study sheds light on the effects of the COVID-19 pandemic on maternal and perinatal healthcare facilities and provides insights for policymakers. The management, allocation, and training of peripartum/perinatal healthcare workers can and must be

\section{REFERENCES}

1. Shereen MA, Khan S, Kazmi A, Bashir N, Siddique R. COVID-19 infection: origin, transmission, and characteristics of human coronaviruses. J Adv Res. (2020) 24:91-8. doi: 10.1016/j.jare.2020.03.005

2. Velavan TP, Meyer CG. The COVID-19 epidemic. Trop Med Int Health. (2020) 25:278-80. doi: 10.1111/tmi.13383

3. Haleem A, Javaid M, Vaishya R. Effects of COVID-19 pandemic in daily life. Curr Med Res Pract. (2020) 10:78-9. doi: 10.1016/j.cmrp.2020.03.011

4. Tanne JH, Hayasaki E, Zastrow M, Pulla P, Smith P, Rada AG. Covid-19: how doctors and healthcare systems are tackling coronavirus worldwide. BMJ. (2020) 368:m1090. doi: 10.1136/bmj.m1090 improved. Italian policymakers and administrators are urged to work together to improve care for the most vulnerable. Prompt and continuous evaluation, along with timely and effective information on the status of healthcare facilities is fundamental to the development and implementation of contextually relevant guidelines.

\section{DATA AVAILABILITY STATEMENT}

The raw data supporting the conclusions of this article will be made available by the corresponding author upon request.

\section{ETHICS STATEMENT}

The studies involving human participants were reviewed and approved by Ethics Committee of ASST Spedali Civili Hospital Brescia, Italy (NP4221 24.06.2020). The patients/participants provided their written informed consent to participate in this study.

\section{AUTHOR CONTRIBUTIONS}

LC and AS contributed equally to the general study design. LC and AT from the Observatory of Perinatal Clinical Psychology promote and coordinate the study in each health care service. MR, SC, and BM designed the plan of statistical analysis of the study. All authors have critically reviewed and agreed this final version of the article.

\section{FUNDING}

This work was funded by the Observatory of Perinatal Clinical Psychology, Section of Neuroscience, Department of Clinical and Experimental Sciences, University of Brescia (Italy).

\section{ACKNOWLEDGMENTS}

We would like to thank the study participants who took time to respond to this survey despite the difficult circumstances and increased workload. We would like to thank all colleagues who distributed the invitation for this survey promoted by the Observatory of Perinatal Clinical Psychology, Section of Neuroscience, Department of Clinical and Experimental Sciences, University of Brescia (Italy).
5. Semaan A, Audet C, Huysmans E, Afolabi B, Assarag B, Banke-Thomas A et al. Voices from the frontline: findings from a thematic analysis of a rapid online global survey of maternal and newborn health professionals facing the COVID-19 pandemic. BMJ Glob Health. (2020) 5:e002967 doi: 10.1136/bmjgh-2020-002967

6. Jha D, Adhikari M, Gautam JS, Tinkari BS, Mishra SR, Khatri RB. Effect of COVID-19 on maternal and neonatal services. Lancet Glob Health. (2021) 9:e114-5. doi: 10.1016/S2214-109X(20)30482-4

7. Cena L, Biban P, Janos J, Lavelli M, Langfus J, Tsai A, Youngstrom EA, Stefana A. The collateral impact of COVID-19 emergency on neonatal intensive care units and family-centered care: challenges and opportunities. Front Psychol. (2021) 12:317. doi: 10.3389/fpsyg.2021.630594 
8. Khalil A, von Dadelszen P, Kalafat E, Sebghati M, Ladhani S, Ugwumadu A et al. Change in obstetric attendance and activities during the COVID-19 pandemic. Lancet Infect Dis. (2020) 21:e115. doi: 10.1016/S1473-3099(20)30779-9

9. Ashish KC, Gurung R, Kinney MV, Sunny AK, Moinuddin MD, Basnet $\mathrm{O}$, et al. Effect of the COVID-19 pandemic response on intrapartum care, stillbirth, and neonatal mortality outcomes in Nepal: a prospective observational study. Lancet Glob Health. (2020) 8:e1273-81. doi: 10.1016/S2214-109X(20)30345-4

10. Green L, Fateen D, Gupta D, McHale T, Nelson T, Mishori R. Providing women's health care during COVID-19: personal and professional challenges faced by health workers. Int J Gynecol Obstet. (2020) 151:3-6. doi: 10.1002/ijgo.13313

11. Mao R, Liang J, Shen J, Ghosh S, Zhu LR, Yang H et al. Implications of COVID19 for patients with pre-existing digestive diseases. Lancet Gastroenterol Hepatol. (2020) 5:426-8.

12. Stefana A, Youngstrom EA, Hopwood CJ, Dakanalis A. The COVID19 pandemic brings a second wave of social isolation and disrupted services. Eur Arch Psychiatry Clin Neurosci. (2020) 270:785-6. doi: 10.1007/s00406-020-01137-8

13. Youngstrom EA, Hinshaw SP, Stefana A, Chen J, Michael K, Van Meter A, et al. Working with bipolar disorder during the covid-19 pandemic: both crisis and opportunity. Wiki J Med. (2020) 7:6. doi: 10.15347/WJM/2020.004

14. Chmielewska B, Barratt I, Townsend R, Kalafat E, van der Meulen J, GurolUrganci I et al. Effects of the COVID-19 pandemic on maternal and perinatal outcomes: a systematic review and meta-analysis. Lancet Glob Health. (2021) 9:e759-72. doi: 10.1016/S2214-109X(21)00079-6

15. Kotlar B, Gerson E, Petrillo S, Langer A, Tiemeier H. The impact of the COVID-19 pandemic on maternal and perinatal health: a scoping review. Reprod Health. (2021) 18:10. doi: 10.1186/s12978-021-01070-6

16. Cena L, Rota M, Calza S, Massardi B, Trainini A, Stefana A. Mental health states experienced by perinatal healthcare workers during COVID19 pandemic in Italy. Int J Environ Res Public Health. (2021) 18:6542. doi: 10.3390/ijerph18126542

17. Horowitz J, Bubola E, Povoledo E. Italy, Pandemic's New Epicenter, Has Lessons for the World. New York Times (2021). Available online at: https://www. nytimes.com/2020/03/21/world/europe/italy-coronavirus-center-lessons. htmlItaly.world/europe/italy-coronavirus-center-lessons.html (accessed April 25, 2021).

18. Grasselli G, Pesenti A, Cecconi M. Critical care utilization for the COVID19 outbreak in Lombardy, Italy: early experience and forecast during an emergency response. JAMA. (2020) 323:1545-6. doi: 10.1001/jama.2020.4031

19. Chirico F, Nucera G. Tribute to healthcare operators threatened by the COVID-19 pandemic. J Health Soc Sci. (2020) 5:165-8. doi: $10.19204 / 2020 /$ trbt1

20. Chirico F, Nucera G, Magnavita N. COVID-19: protecting healthcare workers is a priority. Infect Control Hosp Epidemiol. (2020) 41:1117. doi: $10.1017 /$ ice.2020.148

21. Chirico F, Nucera G, Magnavita N. Hospital infection and COVID-19: do not put all your eggs on the 'swab' tests. Infect Control Hosp Epidemiol. (2020) 42:1-2. doi: $10.1017 /$ ice.2020.254

22. Chirico F, Sacco A, Magnavita N, Nucera G. Coronavirus disease 2019: the second wave in Italy. J Health Res. (2021) 35:359-63. doi: 10.1108/JHR-10-2020-0514

23. Chirico F, Nucera G, Szarpak L. COVID-19 mortality in Italy: the first wave was more severe and deadly, but only in Lombardy region. J Infect. (2021) 83:e16. doi: 10.1016/j.jinf.2021.05.006

24. Istituto Superiore di Sanità. COVID-19 integrated surveillance data in Italy. Available online at: https://www.epicentro.iss.it/en/coronavirus/sars-cov-2dashboard (accessed April 25, 2021).

25. Stefana A, Youngstrom EA, Jun C, Hinshaw S, Maxwell V, Michalak E, Vieta E. The COVID-19 pandemic is a crisis and opportunity for bipolar disorder. Bipolar Dis. (2020) 22:641-3. doi: 10.1111/bdi.12949

26. Indini A, Aschele C, Bruno D, Clerico M, Daniele B, Fiorentini G, et al. Reorganization of medical oncology departments during COVID-19 pandemic: a nationwide Italian survey. Eur J Cancer. (2020) 132:17-23. doi: 10.1016/j.ejca.2020.03.024
27. D’Apolito R, Faraldi M, Ottaiano I, Zagra L. Disruption of arthroplasty practice in an orthopaedic center in northern Italy during COVID-19 pandemic. J Arthroplst. (2020) 35:S6-9. doi: 10.1016/j.arth.2020.04.057

28. Silvagni D, Baggio L, Meragliotta PLT, Soloni P, La Fauci G, Bovo C et al. Impact of COVID-19 pandemic on the characteristics of paediatric emergency room visits in a tertiary centre in Northern Italy. Res Square. (2020). doi: $10.21203 /$ rs.3.rs-61729/v1

29. Jardine J, Relph S, Magee LA, von Dadelszen P, Morris E, Ross-Davie M, et al. Maternity services in the UK during the coronavirus disease 2019 pandemic: a national survey of modifications to standard care. BJOG. (2021) 128:880-9. doi: 10.1111/1471-0528.16547

30. Rimmer AA., Thomas E, Thomas OD, Helme D, Tozer J. Impact of the COVID-19 pandemic on obstetric anaesthesia: a service evaluation. Int J Obstet Anesth. (2021) 46:103041. doi: 10.1016/j.ijoa.2021.103041

31. Suellentrop K, Morrow B, Williams L, D'Angelo D, Centers for Disease Control and Prevention (CDC). Monitoring progress toward achieving Maternal and Infant Healthy People 2010 objectives-19 states, Pregnancy Risk Assessment Monitoring System (PRAMS), 2000-2003. MMWR Surveill Summ. (2006) 55:1-11.

32. Stiggelbout AM, Van der Weijden T, De Wit MP, Frosch D, Légaré F, Montori $\mathrm{VM}$ et al. Shared decision making: really putting patients at the centre of healthcare. BMJ. (2012) 344:344:e256 doi: 10.1136/bmj.e256

33. Harville E, Xiong X, Buekens P. Disasters and perinatal health: a systematic review. Obstetr Gynecol Surv. (2010) 65:713-728. doi: 10.1097/OGX.0b013e31820eddbe

34. Stefana A, Lavelli M. Parental engagement and early interactions with preterm infants during the stay in the neonatal intensive care unit: protocol of a mixed-method and longitudinal study. BMJ Open. (2017) 7:e013824. doi: 10.1136/bmjopen-2016-013824

35. Cena L, Palumbo G, Mirabella F, Gigantesco A, Trainini A, Stefana A. Perspectives on early screening and prompt intervention to identify and treat maternal perinatal mental health. Protocol for a prospective multicenter study in Italy. Front Psychol. (2020) 11:365 doi: 10.3389/fpsyg.2020.00365

36. Ukoha EP, Davis K, Yinger M, Butler B, Ross T, Crear-Perry, et al. Ensuring equitable implementation of telemedicine in perinatal care. Obstetr Gynecol. (2021) 137:487. doi: 10.1097/AOG.0000000000004276

37. Gutiérrez MMC, Durán-Vila A, Ruiz-Labarta J, Payá-Martínez P, Pintado Recarte P, Bujan, J et al. New Multiplatform Model for Outpatient Prenatal and Postpartum Care in a Cohort of COVID-19-Affected Obstetric Patients. Int J Environ Res Public Health. (2021) 18:5144. doi: 10.3390/ijerph181 05144

38. DeMauro SB, Duncan AF, Hurt H. Telemedicine use in neonatal follow-up programs-what can we do and what we can't-lessons learned fromCOVID-19. Semin Perinatol. (2021) 151430. doi: 10.1016/j.semperi.2021.151430

39. Bishop CE, Jackson LE, Vats KR, Azzuqa AA. Prenatal neonatology telemedicine consultation for patients with fetal anomalies during the COVID-19 pandemic era: rapid implementation and lessons learned. $J$ Perinatol. (2020) 40:1451-2. doi: 10.1038/s41372-020-00787-9

40. Jackson LE, Bishop CE, Vats KR, Azzuqa AA. Meeting families where they are: institution, evaluation, and sustainability of telemedicine prenatal neonatology consultation in the COVID-19 pandemic health emergency. Semin Perinatol. (2021) 151417. doi: 10.1016/j.semperi.2021.151417

41. Knight M, Bunch K, Tuffnell D, Shakespeare J, Kotnis R, Kenyon S et al. Saving Lives, Improving Mothers' Care Rapid Report: Learning From SARS-CoV-2Related and Associated Maternal Deaths in the UK March-May 2020. Oxford: National Perinatal Epidemiology Unit, University of Oxford (2020).

42. Moradi F, Ghadiri-Anari A, Enjezab B. COVID-19 and self-care strategies for women with gestational diabetes mellitus. Diabetes Metab Syndr. (2020) 14:1535-9. doi: 10.1016/j.dsx.2020.08.004

43. Rao SP, Minckas N, Medvedev MM, Gathara D, Prashantha YN, Estifanos AS, et al. Small and sick newborn care during the COVID-19 pandemic: global survey and thematic analysis of healthcare providers' voices and experiences. BMJ Glob Health. (2021) 6:e004347. doi: 10.1136/bmjgh-2020-0 04347

44. Gressier F, Mezzacappa A, Lasica PA, Fourcade C, Corruble E. COVID outbreak is changing our practices of perinatal psychiatry. Arch Womens Ment Health. (2020) 23:791-2. doi: 10.1007/s00737-020-01039-7 
45. Carroll WD, Strenger V, Eber E, Porcaro F, Cutrera R, Fitzgerald DA, et al. European and United Kingdom COVID-19 pandemic experience: the same but different. Paediatr Respir Rev. (2020) 35:50-6. doi: $10.1016 /$ j.prrv.2020.06.012

46. Remuzzi A, Remuzzi G. COVID-19 and Italy: what next? Lancet. (2020) 395:1225-28. doi: 10.1016/S0140-6736(20)30627-9

47. Albano D, Bruno A, Bruno F. Impact of coronavirus disease 2019 (COVID19) emergency on Italian radiologists: a national survey. Eur Radiol. (2020) 30:6635-44. doi: 10.1007/s00330-020-07046-7

48. Pecoraro F, Luzi D, Clemente F. Analysis of the different approaches adopted in the italian regions to care for patients affected by COVID19. Int J Environ Res Public Health. (2021) 18:848. doi: 10.3390/ijerph180 30848

49. Magnavita N, Chirico F, Sacco A. COVID-19: from hospitals to courts. Lancet. (2021) 97:1542. doi: 10.1016/S0140-6736(21)00472-4

50. Graham WJ, Afolabi B, Benova L, Campbell OMR, Filippi V, Nakimuli A, et al. Protecting hard-won gains for mothers and newborns in low-income and middle-income countries in the face of COVID-19: call for a service safety net. BMJ Glob Health. (2020) 5:e002754. doi: 10.1136/bmjgh-2020-002754
51. Bradfield Z, Wynter K, Hauck Y, Vasilevski V, Kuliukas L, Wilson AN, et al. Experiences of receiving and providing maternity care during the COVID-19 pandemic in Australia: a five-cohort cross-sectional comparison. PLoS ONE. (2021) 16:e0248488. doi: 10.1371/journal.pone.0248488

52. Saito S, Asai Y, Matsunaga N. First and second COVID-19 waves in Japan: a comparison of disease severity and characteristics. J Infect. (2021) 82:84-123. doi: 10.1016/j.jinf.2020.10.033

Conflict of Interest: The authors declare that the research was conducted in the absence of any commercial or financial relationships that could be construed as a potential conflict of interest.

Copyright (C) 2021 Cena, Rota, Calza, Massardi, Trainini and Stefana. This is an open-access article distributed under the terms of the Creative Commons Attribution License (CC BY). The use, distribution or reproduction in other forums is permitted, provided the original author(s) and the copyright owner(s) are credited and that the original publication in this journal is cited, in accordance with accepted academic practice. No use, distribution or reproduction is permitted which does not comply with these terms. 